\title{
Effects of Forest Regeneration on Crickets: Evaluating Environmental Drivers in a 300-Year Chronosequence
}

\author{
Neucir Szinwelski, ${ }^{1,2}$ Cassiano S. Rosa, ${ }^{3,4}$ José H. Schoereder, ${ }^{5}$ \\ Carina M. Mews, ${ }^{2}$ and Carlos F. Sperber ${ }^{1,2,3}$ \\ ${ }^{1}$ Postgraduate Programme in Entomology, Department of Entomology, Federal University of Viçosa, 36570000 Viçosa, MG, Brazil \\ ${ }^{2}$ Laboratory of Orthoptera, Department of General Biology, Federal University of Viçosa, 36570000 Viçosa, MG, Brazil \\ ${ }^{3}$ Postgraduate Programme in Ecology, Department of General Biology, Federal University of Viçosa, 36570000 Viçosa, MG, Brazil \\ ${ }^{4}$ Faculty of Engineering, State University of Minas Gerais-UEMG, 35930314 João Monlevade, MG, Brazil \\ ${ }^{5}$ Laboratory of Community Ecology, Department of General Biology, Federal University of Viçosa, 36570000 Viçosa, MG, Brazil
}

Correspondence should be addressed to Neucir Szinwelski, neucirufv@gmail.com

Received 1 March 2012; Revised 9 July 2012; Accepted 10 July 2012

Academic Editor: Thomas Iliffe

Copyright ( 2012 Neucir Szinwelski et al. This is an open access article distributed under the Creative Commons Attribution License, which permits unrestricted use, distribution, and reproduction in any medium, provided the original work is properly cited.

\begin{abstract}
We evaluated the relation of cricket species richness and composition with forest regeneration time, evaluating canopy and litter depth as environmental drivers. Effects of forest patch area, nearest distance to the 300 -year patch, cricket abundance, sampling sufficiency, and nestedness were also evaluated. We collected 1174 individuals (five families, 19 species). Species richness increased asymptotically with regeneration time and linearly with canopy cover and litter depth. Canopy cover increased linearly, while litter depth increased asymptotically. Richness was not affected by patch area and nearest distance to the 300-year patch. Richness increased with cricket abundance, and this explanation could not be distinguished from regeneration time, evidencing collinearity of these two explanatory variables. Rarefaction curve slopes increased with regeneration time. Species composition differed among patches, with no nested pattern. We suggest that regeneration and consequent increases in canopy and litter promote recovery of cricket biodiversity, abundance, and changes in species composition. We conclude that the recovery of cricket diversity involves an increase along the spatial scale of complementarity, together with a change in species composition.
\end{abstract}

\section{Introduction}

Forest disturbances may range from simple alterations, such as light gap formation resulting from a toppled tree, to massive damage associated with large storms, hurricanes, fires, and human activities [1]. In tropical ecosystems, human activities—such as logging, mineral extraction, agriculture, and urbanization $[2,3]$ - are largely responsible for forest loss. These activities have caused losses in biodiversity [4] by reducing large areas of old-growth forest to small isolated forest patches. Forest patches are more affected by natural hazards than pristine, large forest areas [5] and are thus more susceptible to further reductions in diversity.

The abandonment of habitat patches, with the subsequent cessation of human activity, allows for forest regeneration and potential biodiversity recolonization $[1,6]$. Forest landscapes are therefore often comprised of patches with different regeneration times [7-9].

Forest regeneration can reduce or eliminate threats to biodiversity [10] by provisioning suitable habitats for endangered species to prevent them from becoming extinct. Forest patches can function as habitat refuges, preserving threatened populations [11], and edge habitats can maintain both old-growth and secondary forest species [12]. Furthermore, forest patches may act as "stepping-stone" habitats that facilitate gene flow among otherwise disconnected forest patches [4]. However, the suitability of secondary forests for maintaining populations depends on the availability of adequate resources and conditions within the habitats of target species [13].

Changes in abundance, diversity, and species composition are commonly associated with succession because of the 
environmental changes that occur during the regeneration process [14]. Several contradictory hypotheses have been proposed [14] to explain various patterns of diversity and species composition in succession gradients: (i) diversity should increase over succession time as the structural complexity of the ecosystem increases [15], or due to facilitation [16]; (ii) all species are present at the beginning of succession and several species may be eliminated by competition [17], resulting in decreased species richness during the succession process; (iii) because of intermediate disturbance effects, species diversity increases from early succession stages to a maximum in mid-succession and decreases during late succession [16, 18-20]; (iv) there is no general pattern of diversity during forest succession [21]; (v) given a uniform environment, with a fixed area, an increase in individuals leads to an increase in species [22].

In the case of litter crickets, the first hypothesis is possibly the most appropriate. Crickets respond to litter disturbance and trampling [23] and changes in environmental conditions, particularly humidity [24]. Given that early regeneration stages represent high-disturbance conditionslow humidity and low structural heterogeneity [25] — low cricket species richness is expected during such periods; therefore, higher richness is likely to be observed as the forest regenerates.

Our aim was to test if cricket species richness and composition responded to regeneration time and to evaluate potential local environmental drivers of species richness, that is, canopy and litter depth. We evaluated eventual landscape configuration effects, namely, forest patch area and nearest distance to the 300-year patch, and the eventual effects of cricket abundance on cricket species richness. Furthermore, we evaluated sampling sufficiency and evaluated if species composition differences could be explained by nestedness.

\section{Methods}

2.1. Study Region. The study was conducted in the Foz do Iguaçu municipality $\left(25^{\circ} 32^{\prime} \mathrm{S}, 54^{\circ} 35^{\prime} \mathrm{E}, 195 \mathrm{~m}\right.$ above sea level), Paraná State, in October 2008. Vegetation is composed of tropical semideciduous forest and ombrophilous mixed forest, within the Atlantic Rainforest biome [26]. The climate in this region can be categorized as humid subtropical mesothermal, with a mean annual temperature of $18-20^{\circ} \mathrm{C}$ and a mean annual rainfall of $1600 \mathrm{~mm}$. The dry and rainy seasons range from April to June and October to January, respectively. Humidity is permanently high, seldom recorded below $80 \%$ even during the driest period [27].

At the time of this sampling, the canopy layer was already homogeneously closed, with most leaves completely developed. Therefore, the canopy layer was close to its maximum productivity, which is attained during the rainy season (N. Szinwelski, personal observations). During occasional observations in the dry season (May and June 2012), we did not observe strong canopy deciduousness.

2.2. Forest Disturbance History. We sampled a chronosequence of seven patches (Figure 1), ranging from zero to
300 years of regeneration (Table 1), from partial to total forest clearing. The patch with zero years of regeneration (Figure 1(a)) was totally cleared. The six-year patch was partially deforested (upper left corner, Figure 1(b)) and had suffered complete burning. The 15-year patch was almost entirely deforested, except for a narrow forest strip along the river which transects the patch longitudinally (Figure 1(c)). The 35- and 70-year patches suffered almost complete deforestation (Figures 1(d)-1(e)). The 130-year patch suffered partial deforestation. There is no recorded history of logging or human disturbance in the 300-year forest patch.

The patches of 0 to 70 years (Figures $1(\mathrm{a})$ to $1(\mathrm{e})$ ) are presently private property; their ages were obtained from information provided by present owners and the descendants of former owners. The 130-year forest patch (Figure 1(f)), located in the Iguaçu River Basin on the western side of Iguaçu National Park [29, 30], was dated with information from the Paraguayan War that occurred between 1864 and 1870 [31]. During the war, the current site of the 130-year forest patch was deforested to build a road and to house troops, as reported by oral histories of local inhabitants. Presently, the 130-year patch is part of the Iguaçu National Park.

Although we assumed an age of 300 years for the oldest forest area (Figure 1(f), 300 years), this is probably an underestimation. The administration of the Iguaçu National Park considers the area, located in the Floriano River Basin, in the eastern region of Iguaçu National Park $[29,30]$, to be untouched wilderness (Marina Xavier and Apolônio Rodrigues, researchers at the Brazilian Institute for the Environment (Instituto Brasileiro do Meio Ambiente (IBAMA), personal observations). The Floriano River Basin is considered the only completely protected river basin in Southern and Southeastern Brazil [32] and was declared a world natural heritage site by UNESCO in 1986 [30].

Although presently the 130- and 300-year study areas belong to the same forest patch in Iguaçu National Park (Figure 1(f)), until 2002 these areas were separated by the Colono Road [30].

2.3. Testing the Assumption. To evaluate the effects of forest regeneration, we estimated regeneration using a continuous, rather than categorical (e.g., initial, intermediate, and late succession) approach. To achieve this, we used only the seven forest patches in the studied region for which precise knowledge of regeneration time was available. An increase in the number of sampled patches would only be possible if we included patches with inexact regeneration time data, which would jeopardize our approach.

At each forest patch, at least $200 \mathrm{~m}$ from the patch border, we placed 10 sets of pitfall traps parallel to each other at $15 \mathrm{~m}$ intervals, with each set consisting of a line of 5 traps $1 \mathrm{~m}$ apart. Each pitfall trap contained a solution of $80 \%$ ethanol, $10 \%$ formaldehyde, and $10 \%$ glycerin as a killing and preservative agent, as recommended by Sperber et al. [33]. The traps were maintained in the field for 48 hours, after which they were collected, and the crickets were 


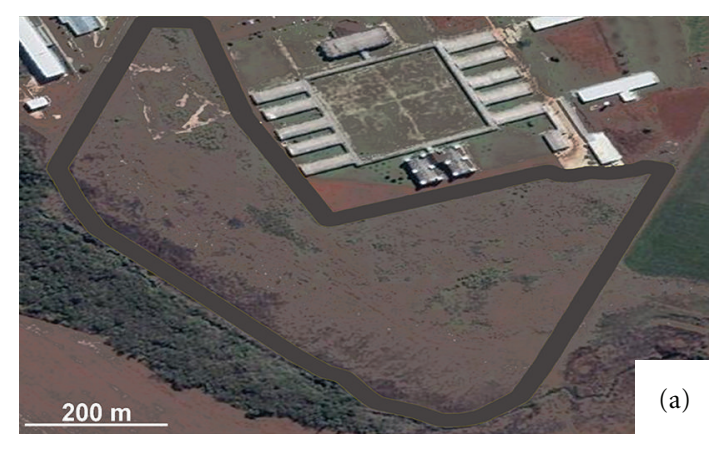

(a)

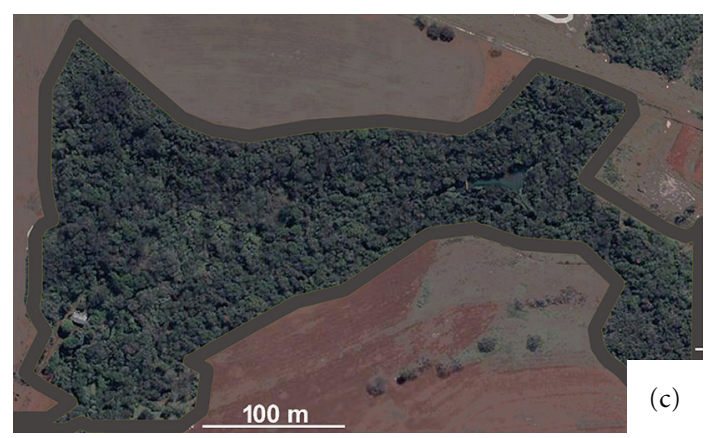

(c)

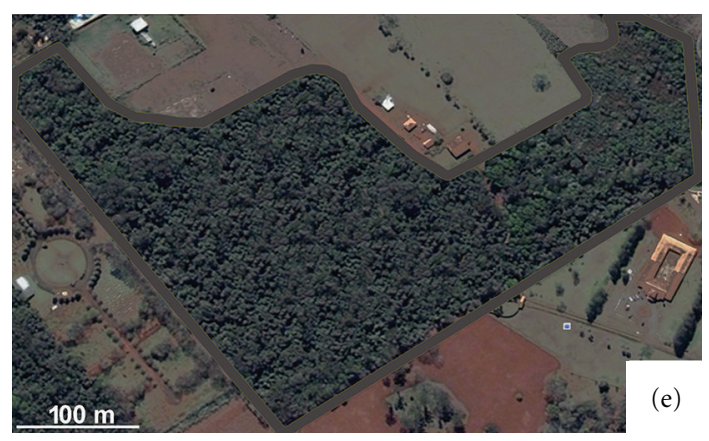

(e)

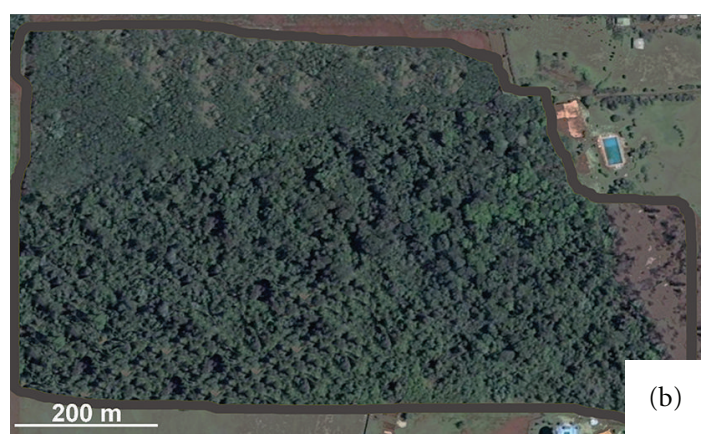

(b)

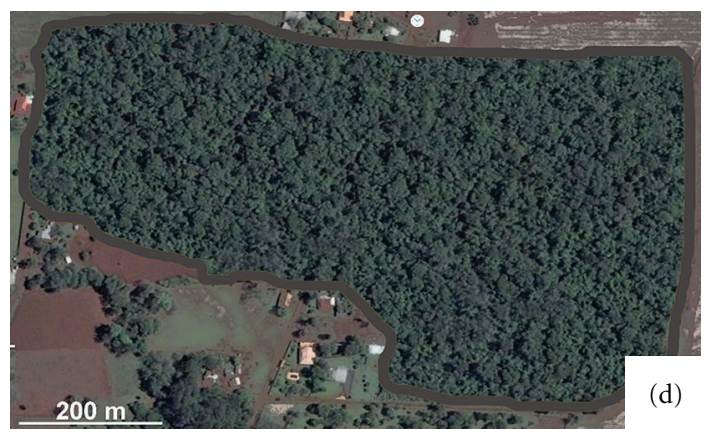

(d)

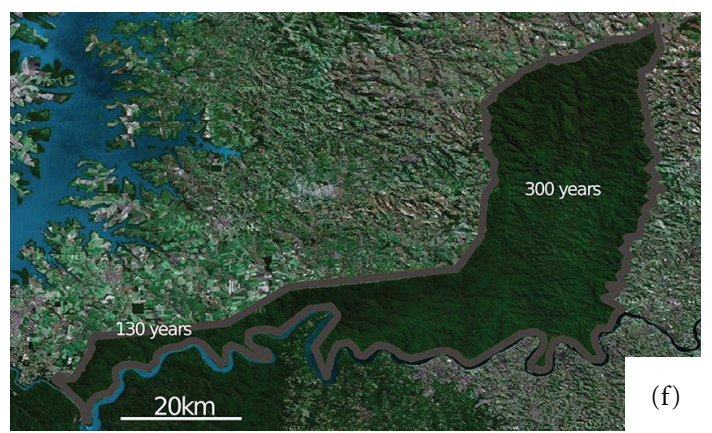

(f)

FIGURE 1: Study areas, with the following years of regeneration: (a) zero; (b) six; (c) fifteen, (d) thirty-five; (e) seventy; (f) 130 and 300 years (Iguaçu National Park). Source: [28]. For additional information, see Table 1.

TABLE 1: Characteristics of the sampled forest patches. Geographical coordinates correspond to the central point in each patch.

\begin{tabular}{llll}
\hline $\begin{array}{l}\text { Regeneration } \\
\text { time (years) }\end{array}$ & Geographical coordinate & Area (ha) & $\begin{array}{c}\text { Distance to } \\
300-\text { year patch }\end{array}$ \\
\hline 0 & $25^{\circ} 28^{\prime} 05^{\prime \prime}-54^{\circ} 34^{\prime} 12^{\prime \prime}$ & 21.29 & 25 \\
6 & $25^{\circ} 34^{\prime} 19^{\prime \prime}-54^{\circ} 30^{\prime} 41^{\prime \prime}$ & 44.25 & 25 \\
15 & $25^{\circ} 27^{\prime} 51^{\prime \prime}-54^{\circ} 34^{\prime} 40^{\prime \prime}$ & 6.35 & 8 \\
35 & $35^{\circ} 35^{\prime} 02^{\prime \prime}-54^{\circ} 30^{\prime} 06^{\prime \prime}$ & 36.09 & 15 \\
70 & $25^{\circ} 33^{\prime} 03^{\prime \prime}-54^{\circ} 33^{\prime} 16^{\prime \prime}$ & 6.66 & 45 \\
130 & $25^{\circ} 37^{\prime} 54^{\prime \prime}-54^{\circ} 27^{\prime} 38^{\prime \prime}$ & 35000 & 150000 \\
300 & $25^{\circ} 13^{\prime} 41^{\prime \prime}-53^{\circ} 44^{\prime} 57^{\prime \prime}$ & 0 & 45 \\
\hline
\end{tabular}


sorted and stored in $80 \%$ ethanol. Voucher specimens were deposited in the Laboratory of Orthoptera, part of the Museu Regional de Entomologia da Universidade Federal de Viçosa (UFVB).

2.4. Potential Local Environmental Drivers. To evaluate potential environmental drivers of the cricket community, we measured litter and canopy structure. Litter depth was measured with a ruler at each trap. Mean litter depth was based on 50 samples per unit area.

To evaluate canopy cover, we took photographs at the intersection of each set of traps along the transect in each area, using a digital camera (CANON EOS 350D Digital Rebel) with a fish-eye lens (Canon EF $15 \mathrm{~mm}$ $\mathrm{f} / 2.8$ ), positioned $1 \mathrm{~m}$ above ground level. The percentage of canopy cover was calculated using the program Gap Light Analyzer (GLA) [34]. For evaluation purposes photographs were converted into black and white, so that the amount of white pixels could be calculated (as a direct estimate of light penetration and an inverse estimate of cover) using GLA software. Canopy cover was calculated as the mean of the 10 samples from each area.

2.5. Landscape Configuration Effects. To evaluate if landscape configuration affected cricket species richness, we measured forest patch area and nearest distance to the 300-year patch using satellite images [28] and land title deed data provided by the land owners. We considered the distance to the 300-year patch as an estimate of species dispersal distance, because in addition to being the most preserved forest patch, it is also the largest continuous forest area in the region $(135,000$ ha $+50,000$ ha of the 130 -year patch, to which it is currently connected).

\subsection{Data Analysis}

2.6.1. Testing the Assumption. To test the assumption that cricket species richness increased with forest regeneration time, we adjusted generalized linear models (GLMs) with Poisson's errors, with accumulated species number per patch as response variable and regeneration time as an explanatory variable ( $n=7$, Figure 1$)$. We used Chi-square $\left(\chi^{2}\right)$ test for Poisson's distributions and the $F$ test when over- or under-dispersion was corrected, as recommended by Crawley [35] and Zuur et al. [36]. To evaluate the significance of the explanatory variable, we used stepwise backward model simplification, using the $P$ value to exclude nonsignificant variables. Adjusted models were subjected to residual analyses, to evaluate the adequacy of the model. We detected evidence of nonlinearity that was not adequately modeled by including a quadratic term in a polynomial regression. We therefore adjusted nonlinear regression ( $n l s$ procedure in $R$ ) with asymptotic models and evaluated the adequacy of the adjusted models by visual inspection of the predicted and observed values. Comparison of Akaike's information criterion (AIC) of the models was not available because the linear model presented overdispersion; therefore it did not provide this index.
2.6.2. Testing the Potential Local Environmental Drivers. To evaluate the potential local environmental drivers of cricket response to regeneration time, we tested the hypothesis that the variation in cricket species richness with regeneration time was driven by canopy cover and litter depth. We adjusted separate GLMs with cricket species richness and potential local environmental drivers as response variables. To avoid pseudoreplication, we considered the forest patches as our sampling unit ( $n=7$; Figure 1$)$, using the mean values for litter depth and canopy cover per forest patch. For models with species richness as the response variable, we used Poisson's errors, and corrected for under- or overdispersion when necessary. For models with litter depth as the response variable, we used normal errors, since depth is a continuous variable. For models with canopy cover percentage as the response variable, we used binomial errors corrected for continuous data, since canopy cover is a proportion.

To evaluate the significance of the explanatory variable, we used stepwise backward model simplification, using the $P$ value to exclude nonsignificant variables. Adjusted models were subjected to residual analyses, to evaluate model adequacy. If an environmental variable was an effective driver of the response of richness to regeneration time, we expected that richness would be affected by this variable and that the variable would correlate to regeneration time.

We detected evidence for nonlinearity in the relationship of litter depth with regeneration time. This could not be adequately modeled by including a quadratic term in a polynomial regression, so we adjusted nonlinear regression ( $n l s$ procedure in $R$ ) with asymptotic models and evaluated the adequacy of the adjusted models by visual inspection of the predicted and observed values. We used AIC values to choose the most adequate model.

2.6.3. Testing Landscape Configuration Effects. To evaluate if landscape configuration explained the response of cricket species richness to forest regeneration time, we adjusted GLMs with species richness as the response variable, regeneration time as the explanatory variable, and patch area and nearest distance to the 300-year patch as covariables, adjusted logistic multiple regression with Poisson's errors, and adjusted for under- or overdispersion as necessary. The complete model to evaluate the effects of landscape configuration included all interaction terms. To evaluate the significance of the explanatory variable, we used stepwise backward model simplification, using the $P$ value to exclude nonsignificant variables. Adjusted models were subjected to residual analyses to evaluate model adequacy.

\subsubsection{Testing for the Effects of Cricket Abundance on Cricket} Species Richness. To evaluate if cricket abundance would explain cricket species richness, we adjusted GLMs with cricket species richness per patch as the response variable $(n=7)$, regeneration time as the explanatory variable, and cricket abundance as the covariable, adjusted logistic multiple regression with Poisson's errors, and adjusted for under- or overdispersion as necessary. The complete model to evaluate the effects of cricket abundance on the studied 
relationships included all interaction terms. To evaluate the significance of the explanatory variable, we used stepwise backward model simplification, using the $P$ value to exclude nonsignificant variables. Adjusted models were subjected to residual analyses to evaluate model adequacy.

Cricket abundance was estimated by the total number of individuals captured in the 50 traps of each studied patch. Eventual significance of abundance effects on species richness was interpreted as passive sampling [37], where patches with more individuals presented larger species richness.

All univariate analyses were done within the $R$ environment [38].

2.6.5. Testing for Sampling Sufficiency. To evaluate sampling sufficiency for estimating the species richness of each patch, we used individual-based rarefaction analysis [39], comparing species richness accumulation curves among patches by visual assessment of overlapping 95\% confidence intervals. Rarefaction analysis was done in EstimateS 7.5 [40].

2.6.6. Testing for Effects of Regeneration Time on Cricket Species Composition. To evaluate if species composition differed among forest patches, we considered each group of five pitfall traps as our sampling unit $(n=70)$, to evaluate if the variation within patches was larger than the variation among patches. We assumed that species composition differed among patches when sampling units of a particular patch were more similar to each other than to those from different forest patches. To analyze the similarity among samples, we used nonmetric multidimensional scaling (NMDS), running 10,000 permutations and using the Bray-Curtis distance to explore differences in community structure across the patches.

We used the stress value to assess the robustness of the NMDS solution, as stress values above 0.2 indicate plots that may be unreliable [41]. Analysis of similarity (ANOSIM) was used to test if there were significant differences in multivariate community structure among forest patches. The null hypothesis was that there would be no differences among forest patches. ANOSIM is a nonparametric permutation test for similarity matrices analogous to analysis of variance (ANOVA) [41]. We used similarity percentage analysis (SIMPER) to evaluate which species are more relevant to group forming. All multivariate analyses were undertaken using PAST software [42].

2.6.7. Nestedness Analyses. To evaluate if species composition differences could be explained by nestedness, that is, if cricket species in forest patches with lower species richness were a subset of the species present in higher-richness sites [43, 44 ], we measured the degree of nestedness of the cricket assemblages from the seven forest patches using the "vegan" library [45] of the $R$ environment [38]. We calculated the NODF (nestedness metric based on overlap and decreasing fill) statistics [46], running 10,000 simulations using the " $r 1$ " method, which uses both row and column constraints as recommended by Ulrich et al. [44]. The NODF statistics vary

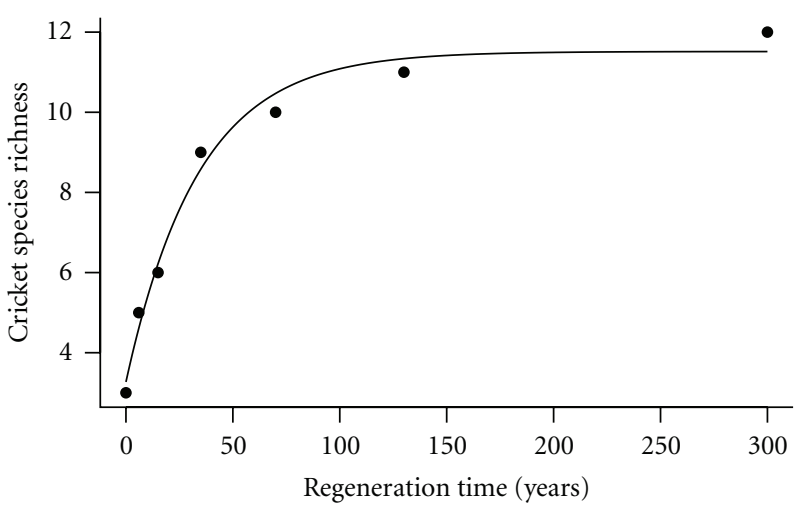

FIGURE 2: Response of cricket species richness to regeneration time. Species richness increased asymptotically up to 130 years of regeneration. Nonlinear regression with Gaussian errors: $y=$ $11.293-8.081^{(-0.003 * x)} ; F_{2,4}=16.16 ; P=0.012$.

from 0 to 100 , with 100 representing maximum nestedness [47].

\section{Results}

3.1. Cricket Fauna. We collected 1174 individuals belonging to five families and 19 species. The richest and most abundant family was Phalangopsidae (12 species: 983 individuals), followed by Trigoniidae (two species: 107 individuals), Eneopteridae (two species: nine individuals), Gryllidae (two species: 70 individuals), and Mogoplistidae, which had only one species and five individuals (Table 2). Crickets of the Gryllidae family occurred only in areas with zero years of regeneration (open habitat) and were absent from the remaining areas, while five species of Phalangopsidae were exclusive to older forests (Table 2).

3.2. Testing the Assumption. Using linear regression, we detected that cricket species richness increased with forest regeneration time (overdispersion; $F_{1,5}=22.37 ; P=0.005$ ), but there was strong evidence of nonlinear relation. The relationship between species richness and regeneration time was adequately modeled by the following asymptotic equation:

$$
y=11.293-8.081^{(-0.003 * x)} .
$$

Therefore, cricket species richness increased asymptotically with regeneration time until stabilizing at 130 years of regeneration (nonlinear regression; Figure 2).

3.3. Local Environmental Drivers. Cricket species richness increased with percentage of canopy cover $\left(\chi^{2}=3.97 ; P=\right.$ 0.046; Figure 3) and litter depth $\left(\chi^{2}=8.15 ; P=0.004\right.$; Figure 4).

Canopy cover increased with forest regeneration time $\left(F_{1,4}=54.24 ; P=0.018\right.$; Figure 5$)$. Litter depth was not linearly related to regeneration time $\left(F_{1,5}=5.30 ; P=0.06\right)$, but there was a strikingly nonlinear relationship. When using nonlinear regression to adjust an asymptotic model, the relationship between litter depth and regeneration time was 
TABle 2: Cricket taxa, number of individuals per forest patch, and taxa contribution to species composition groups forming in SIMPER analysis (taxon alone (A), percent value (\%), and taxon order (B)). Taxa were ordered according to contribution (B). Taxa not assigned to described species or genus received number codes. All unidentified crickets belong to taxa that had not been previously collected and are therefore new to science.

\begin{tabular}{|c|c|c|c|c|c|c|c|c|c|c|c|}
\hline \multirow{2}{*}{ Taxons } & \multicolumn{7}{|c|}{ Forest patches years } & \multicolumn{4}{|c|}{ Taxa contribution } \\
\hline & 0 & 6 & 15 & 35 & 70 & 130 & 300 & Total & A & $\%$ & B \\
\hline Ectecous sp.1 & - & 85 & 33 & 34 & 157 & 147 & 194 & 650 & 32.82 & 44.78 & 1 \\
\hline Phoremia sp.1 & - & - & - & 85 & 5 & 5 & 10 & 105 & 8.43 & 56.28 & 2 \\
\hline Gryllus assimilis & 49 & - & - & - & - & - & - & 49 & 6.86 & 65.64 & 3 \\
\hline Lerneca sp.1 & 6 & 45 & 30 & - & 23 & - & - & 104 & 6.36 & 74.32 & 4 \\
\hline Laranda sp.1 & - & 10 & 16 & 27 & 10 & 12 & 4 & 79 & 4.82 & 80.9 & 5 \\
\hline Vanzoliniella sp.1 & - & 9 & 24 & 23 & 8 & - & - & 64 & 4.19 & 86.61 & 6 \\
\hline Aracamby sp. 1 & - & - & - & 3 & 15 & 8 & 10 & 36 & 2.36 & 89.83 & 7 \\
\hline Aracamby sp. 2 & - & - & - & - & - & 14 & 17 & 31 & 2.33 & 93.02 & 8 \\
\hline Miogryllus sp.1 & 5 & 16 & - & - & - & - & - & 21 & 1.89 & 95.6 & 9 \\
\hline Adelosgryllus rubricephalus & - & - & 2 & 2 & 1 & 1 & 1 & 7 & 0.62 & 96.45 & 10 \\
\hline Eneoptera surinamensis & - & - & 5 & - & - & - & - & 5 & 0.61 & 97.29 & 11 \\
\hline Mogoplistidae Genus 3 sp.1 & - & - & - & 1 & 1 & 2 & 1 & 5 & 0.47 & 97.93 & 12 \\
\hline Phalangopsidae Genus 1 sp. 1 & - & - & - & - & - & 3 & 1 & 4 & 0.39 & 98.46 & 13 \\
\hline Tafalisca sp.1 & - & - & - & 2 & 1 & - & 1 & 4 & 0.34 & 98.94 & 14 \\
\hline Phalangopsidae Genus 2 sp.2 & - & - & - & - & - & 1 & 2 & 3 & 0.24 & 99.27 & 15 \\
\hline Eidmanacris tridentata & - & - & - & - & - & 1 & 1 & 2 & 0.17 & 99.5 & 16 \\
\hline Endecous sp. 1 & - & - & - & - & - & 1 & 1 & 2 & 0.16 & 99.73 & 17 \\
\hline Zucchiella sp.1 & - & - & - & - & 2 & - & - & 2 & 0.13 & 99.91 & 18 \\
\hline Eidmanacris bidentata & - & - & - & 1 & - & - & - & 1 & 0.06 & 100 & 19 \\
\hline Individuals & 60 & 165 & 110 & 178 & 223 & 195 & 243 & 1174 & - & - & - \\
\hline Species & 3 & 5 & 6 & 9 & 10 & 11 & 12 & 19 & - & - & - \\
\hline
\end{tabular}

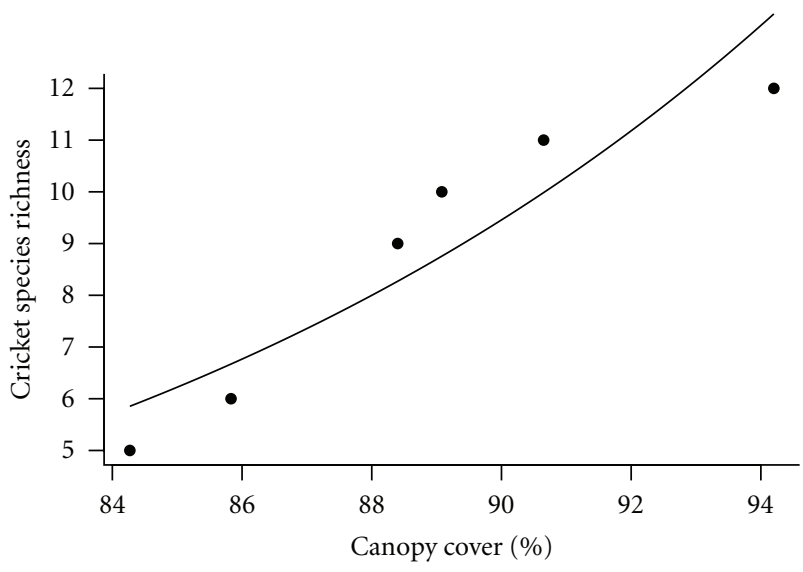

Figure 3: Response of cricket species richness to canopy cover. Species richness increased linearly with canopy cover. Linear regression with Poisson's errors: $y=e^{(-5.285+0.083 * x)} ; \chi^{2}=3.97 ; P=$ 0.046 .

adequately modeled $\left(F_{2,4}=8.78 ; P=0.034\right.$; Figure 6$)$ by the following equation:

$$
y=e^{(0.894+0.328 * x)}
$$

3.4. Landscape Configuration Effects. Neither patch area nor nearest distance to the 300-year patch had any effect on

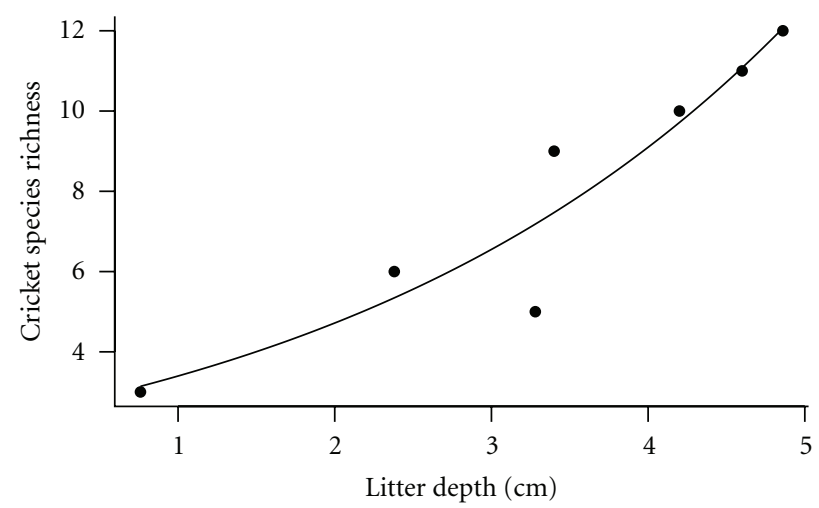

FIgURE 4: Response of cricket species richness to litter depth. Species richness increased linearly with liter depth. Linear regression with Poisson's errors: $y=e^{(0.894+0.328 * x)} ; \chi^{2}=8.15 ; P=0.004$.

cricket species richness $\left(\chi^{2}=3.24 ; P=0.07\right.$ and $\chi^{2}=0.25$; $P=0.61$, resp.).

3.5. Effects of Cricket Abundance on Cricket Species Richness. There was no interaction effect of patch regeneration time with cricket abundance $\left(F_{1,4}=4.06 ; P=0.13\right)$. The deletion of both cricket abundance and regeneration time was nonsignificant when compared to a model maintaining one of these explanatory variables ( $Y$ abundance + time 


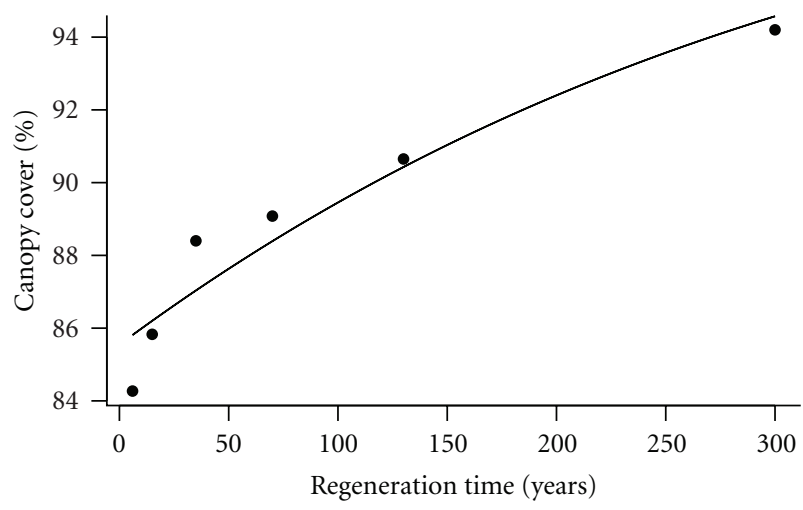

Figure 5: Response of canopy cover to regeneration time. Canopy cover increased linearly with regeneration time. Linear regression with binomial errors: $y=100 * e^{(1.778+0.003 * x)} / 1+e^{(1.778+0.003 * x)} ; F_{1,4}=$ 54.24; $P=0.018$.

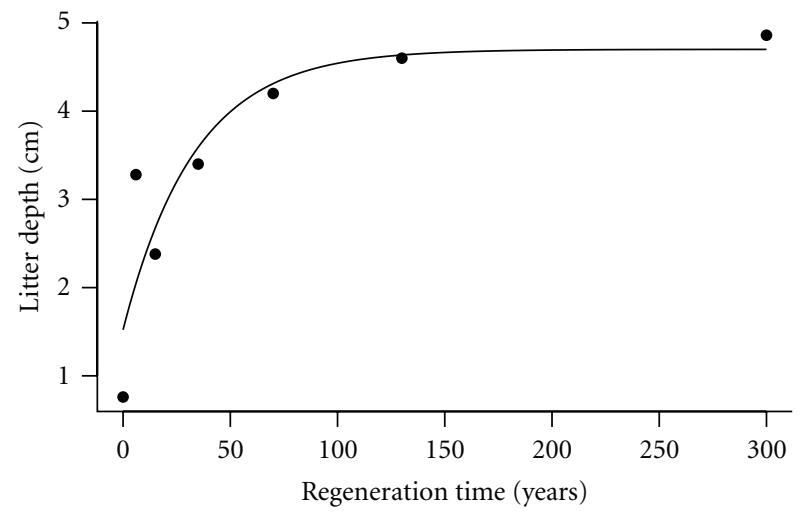

FIGURE 6: Response of litter depth to regeneration time. Litter depth increased asymptotically up to 130 years of regeneration. Nonlinear regression with Gaussian errors: $y=e^{(0.894+0.328 * x)} ; F_{2,4}=8.78 ; P=$ 0.034 .

versus $Y$ abundance; $F_{1,5}=6.92 P=0.068 ; Y$ abundance + time versus $Y$ time $\left.F_{1,4}=0.11 ; P=0.75\right)$. When compared to the null model, however, both explanatory variables significantly affected cricket species richness ( $Y$ abundance versus $Y 1 ; F_{1,5}=5.52 ; P=0.045$ and $Y$ time versus $Y 1$; $\left.F_{1,5}=22.37 ; P=0.005\right)$. Therefore, cricket species richness per patch could be explained both by regeneration time and cricket abundance.

3.6. Sampling Sufficiency. Although we detected no statistical difference in rarefaction curves among forest patches, the slopes of the rarefaction curves increased with regeneration time (Figure 7). The bias of the estimated species richness increased, in correlation with the regeneration time. In the most recent forest patches (zero to 15 years of regeneration), species richness was fully sampled, while the rarefaction curves in all remaining, older, patches showed that we did not reach the actual species richness. Therefore, the rarefaction curves reinforce the pattern of increasing species richness with regeneration time.

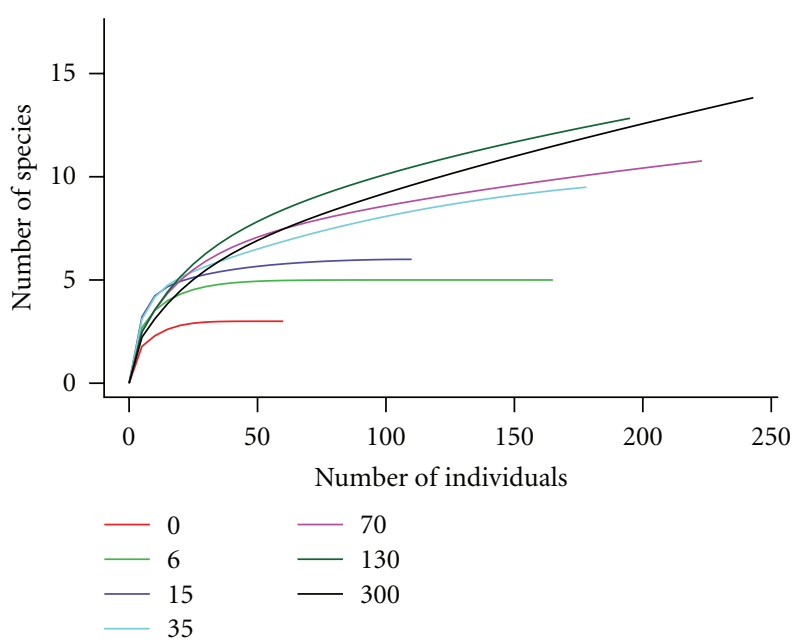

FIGURE 7: Individual-based species rarefaction curves for crickets communities within different forest patches. All 95\% confidence intervals (CI) overlapped, showing that there was no significant difference between forests patches. We removed the dotted lines that represent $\mathrm{CI}$, so as to allow visualization of trends.

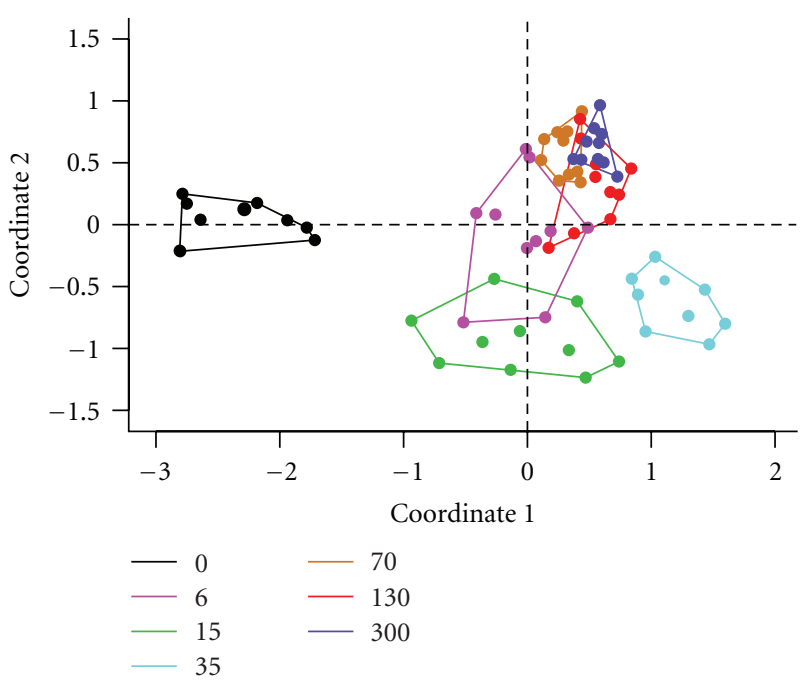

Figure 8: Plot of nonmetric multidimensional scaling (NMDS) ordination, showing difference between areas: stress $0.1401 ; P<$ 0.001 . Colors correspond to regeneration time, varying from 0 to 300 years.

3.7. Effects of Regeneration Time on Cricket Species Composition. Species composition was different among all forest patches (Stress 0.1401; $P<0.001$; Figure 8), with ANOSIM indicating complete separation among patches $(R=0.75$; $P$ (same) $<0.0001$; Bonferroni $P$ values for each patch combination $<0.03$; Table 3 ).

The SIMPER (Table 2: taxa contribution) showed that Ectecous sp. 1 and Phoremia sp. 1 were the two most relevant species for group forming in the species composition NMDS analysis, with $45 \%$ and $56 \%$ cumulative contribution, sequentially. 
TABLE 3: Analysis of similarity (ANOSIM) results, showing, Bonferroni-corrected $P$ values for the null hypotheses that forest patch species composition is the same for each patch combination. Permutation number $=10,000$; mean rank within $=419.6$; mean rank between $=1326$; $R=0.7509$; overall $P$ (same) $<0.0001$; distance measure: Bray-Curtis.

\begin{tabular}{|c|c|c|c|c|c|c|c|}
\hline \multirow{2}{*}{$\begin{array}{l}\text { Forest patch } \\
\text { (regeneration time) }\end{array}$} & \multicolumn{7}{|c|}{ Forest patch (regeneration time) } \\
\hline & 0 & 6 & 15 & 35 & 70 & 130 & 300 \\
\hline 0 & - & 0 & 0 & 0 & 0 & 0 & 0 \\
\hline 6 & 0 & - & 0.0007 & 0.0001 & 0 & 0 & 0 \\
\hline 15 & 0 & 0.0007 & - & 0 & 0 & 0 & 0 \\
\hline 35 & 0 & 0.0001 & 0 & - & 0.0001 & 0 & 0 \\
\hline 70 & 0 & 0 & 0 & 0.0001 & - & 0.0004 & 0.0039 \\
\hline 130 & 0 & 0 & 0 & 0 & 0.0004 & - & 0.0244 \\
\hline 300 & 0 & 0 & 0 & 0 & 0.0039 & 0.0244 & - \\
\hline
\end{tabular}

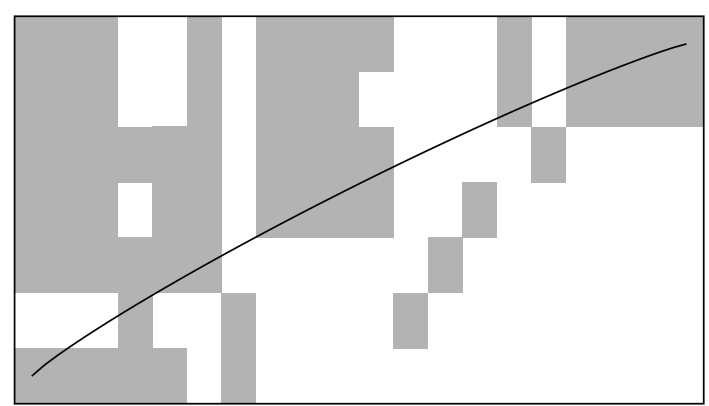

Figure 9: Presence (gray) or absence (white) of the 19 species (columns) in each of the seven forest patches (rows). For nested pattern, all species should appear above the curve. The result shows that species composition was not nested.

3.8. Nestedness Analyses. Species composition showed no nested pattern $(\mathrm{NODF}=51.72 ; P=0.84$; Figure 9).

\section{Discussion}

4.1. Cricket Fauna. The exclusiveness of the Gryllidae family to open habitat coincides with previous observations [48] that this family is typical of open areas, in contrast to Phalangopsidae and Trigoniidae, which are characteristic of forest habitat. Open areas facilitate flight and allow sound to spread easily [49], leading to a predominance of winged species with well-developed posterior wings, which are responsible for flight [50]. Among the Gryllidae, most species had welldeveloped hindwings and stridulatory apparatus for acoustic communication [51]. This may explain why Gryllidae were restricted to the open area.

Sound propagation is limited in forest habitats, which may represent a selective pressure against acoustic communication $[49,52]$. In forested areas, apterous species and those without posterior wings predominate, particularly in the case of litter crickets (C.F. Sperber, personal observations). Such species are unable to fly [53]. The loss of forewings implies the loss of stridulatory capacity. As a probable alternative form of communication, many litter cricket species have secretory external glands used in pre- and postcopulatory behavior. All of the Phalangopsidae that we collected lacked posterior wings, with the exception of Lerneca sp.1 (Grylloidea: Phalangopsidae).

Lerneca sp. 1 presents developed posterior wings, similar to those of Eneoptera surinamensis (Grylloidea: Eneopteridae). Both species are good fliers and may be especially well adapted to dispersion. Although we collected E. surinamensis in only one area, this species is common in disturbed forest habitats [54].

Forest Phalangopsidae generally have slender, poorly chitinized bodies, which makes them more prone to desiccation and therefore dependent on humid conditions. This may explain their high abundance in regenerated forests. In contrast to the slender body of forest Phalangopsidae, the body of Lerneca is more robust and chitinized, making this taxon less dependent on humid conditions. Similarly, E. surinamensis also has a robust, strongly chitinized body and is not dependent on high humidity. This species probably absorbs water for metabolism from its diet, and its phenology is synchronized to seasonal water availability, remaining as nymphs (which are vulnerable to desiccation) during the rainy season and developing into adults in the dry season [55]. Similar adaptations may occur in Lerneca sp.1. The above characteristics explain why these two species are commonly collected in less regenerated forests.

The Phalangopsidae genera Eidmanacris, Endecous, and Aracamby are usually associated with less disturbed forests, being dependent on high humidity in the soil, shelter in armadillo holes, tree holes, or gaps formed by fallen logs [56]. Phoremia and Zucchiella (Trigoniidae) are recorded as associated with less disturbed forests [57] and use litter for displacement and sheltering [23].

The predominance of the Phalangopsidae species Ectecous sp.1, in relation to the Trigonidiidae species Phoremia sp. 1 in regenerated forests (Table 2), contrasts with findings from other Atlantic Rainforest patches, where Trigonidiidae predominate [23]. This may be a result of topographical differences between the two studies: the areas studied here occur in flat topography, whereas Phoremia predominates in areas with a more pronounced topography, particularly hilly domains [58]. Another factor explaining the contrasting results of these studies is that the size of the forest patches 
studied differed: while the size of the patches in this study varied from seven to 150 thousand hectares, forest patches where Phoremia predominates were all less than 350 ha [23]. Smaller areas are more susceptible to abiotic disturbances, such as edge effects [11, 59], and anthropogenic disturbances, such as selective logging [60]. If this is the case, then the predominance of Ectecous in Atlantic Rainforest litter could be regarded as an indicator of the degree of forest preservation.

4.2. Species Richness Response to Regeneration. The asymptotic response of cricket species richness to regeneration time (Figure 2) suggests that species accumulation occurs in two distinct phases. Species richness increases up to ca. 130 years of regeneration, when a local limit may be reached. However, we must take the asymptotic stabilization of species richness with regeneration time with caution, since the bias of the estimated species richness also increased with regeneration time, as depicted by the increasing slope of the rarefaction curves with regeneration time (Figure 7). At the spatial scale sampled here, however, our results show a trend of local species richness stabilizing with regeneration time, contrasting with a continuous change in species composition (Figure 8).

The asymptotic response of cricket species richness to forest regeneration could be interpreted as "how much is enough?" [61]; that is, a regeneration period of 130 years would be enough to restore original species richness. However, the continuity of the directional change in species composition may be regarded as evidence that this interpretation is incorrect. Although species richness did not change from 130 to 300 years of regeneration, species composition continued to change.

The asymptotic accumulation of cricket species differs from the patterns proposed in the literature. The observed response may be a subtle divergence from the constant increase expected by Clements [15]. On the other hand, the asymptotic response could correspond to the initial portion of the humpback pattern expected by intermediate disturbance [18]. Larger time spans would highlight the decreasing portion of the humpback pattern. Rosenzweig [62] already suggested that such partial gradient responses to explain contradictory patterns of increase and decrease of richness with succession.

Our chronosequence is, however, old enough to test whether further changes occurred over a longer time period. Our highest regeneration time was of at least 300 years. Any disturbance in this area would have been restricted to forest use by Amerindians, prior to European colonization of Brazil. Estimates of human population size at the time of first European contact range from 1 to 5 million, but the indigenous population has now declined to about 185,000 [63]. Moreover, according to the present knowledge, forest use and disturbance by Amerindians would have been spatially and temporary restricted [64]. Amerindians generally built in natural clearings, with selective logging and no pruning of roots [65]. We therefore believe that disturbances caused by Amerindians were spatially and temporarily restricted, and that the eventual effects of such disturbances upon forest litter communities would not persist until today.

4.3. Local Environmental Drivers. The mechanisms involved in the increasing levels of species richness include canopy cover and litter accumulation. However, the coincidence of the asymptotic litter response curve to regeneration (Figure 6) suggests that this environmental variable is fundamental to determining cricket species richness. The limit to species accumulation suggests that there is some kind of saturation point, mediated through competitive or other biotic interactions [10]. Litter depth could possibly correlate to shelter availability. Shelter within litter could provide both enemy protection [66] and favorable humidity conditions [24]. Species saturation could, therefore, be determined by bottom-up as well as top-down control mechanisms [67, 68]. If this is the case, litter cricket communities of old tropical forests might be saturated, even though competition for food is not apparent: crickets are omnivores, thus probably generalists; therefore food resources are probably not limiting. Shelter from natural enemies or suitable oviposition sites with more favorable environmental conditions may be limiting factors for litter crickets. Thus it is possible that crickets compete for these resources, creating a limit to species richness.

4.4. Environmental Drivers: Canopy Cover. The increase of canopy cover with regeneration time (Figure 5) leads to lower temperature variability and lower evaporation of soil water [66]. High temperature variation-typical of early succession stages [69]—can exceed insect thermoregulatory capacities, affecting development and survival [70]. Furthermore, variations in temperature can induce diapause in insects [71], resulting in a decreased metabolic rate [72] and compromised immune response [73] — which ultimately affects locomotion and reproduction [74, 75]. Increased canopy cover may therefore represent an increase in cricket habitat suitability [76], driving the observed increase in species richness (Figure 3).

Humidity affects reproduction in insects [77]. Since the reproductive rate of crickets may be reduced during low humidity conditions [24], it can be expected that a higher reproductive rate would be achieved in environments with greater canopy cover. Humidity can also affect insect locomotion, since it influences soil adhesiveness [74]. Litter crickets move by means of walking and jumping, and locomotion efficiency can also impact mating success and predation avoidance. High humidity may increase fungus development [78], which may reduce food palatability and facilitate the growth of toxin-producing entomopatogenic fungi [79] that can be lethal to insects (but see Elliot et al. [73]). Excessively high humidity may therefore be harmful to litter crickets.

Canopy cover can be correlated to the production of foods, such as fruits that are a common resource for litter crickets. Canopy cover can also be correlated to increased habitat structural complexity [80] resulting in increased litter depth. Litter may provide food resources [81, 82], 
and a deeper leaf-litter layer could also provide a refuge for crickets to maintain humidity during the dry season; thus buffering population declines during such periods [83]. Litter is also important for the provision of nesting sites, especially for species that oviposit directly into the soil or litter components [84].

4.5. Environmental Drivers: Litter Depth. Litter depth responded asymptotically to regeneration time, stabilizing at 130 years (Figure 6), which converges with the observed response of species richness (Figure 2). We suggest that this parameter is the strongest environmental driver of cricket species richness. The stabilization of litter depth with increasing canopy cover may result from an increase in decomposition rate in old-growth forest [85]. High production of leaf litter thus corresponds with a high rate of decomposition.

4.6. Effects of Cricket Abundance on Cricket Species Richness. Our statistical results were inconclusive between choosing regeneration time or cricket abundance to explain species richness per patch. This doubt characterizes collinear explanatory variables $[35,36]$. Collinearity occurs when explanatory variables covary in the field, with both variables contributing to the observed pattern. Therefore, both cricket species richness and abundance increased with forest regeneration time. One effect cannot be discussed separately from the other. We interpret these correlations as evidence of increasing habitat quality for crickets during forest regeneration.

4.7. Sampling Sufficiency. For the older ( 35 years or more) forest patches, the rarefaction curves suggest that the cricket species richness was undersampled, since there was no distinguished stabilization in the species accumulation curves (Figure 7). Although intensive sampling in the most preserved patch (300 years), done for taxonomy purposes (Francisco A. G. de Mello and Pedro G. Dias, personal communication), resulted in 25 cricket species (compared to 19 found here); thirteen of these cricket species live in tree trunks, shrubs, and canopy (Pedro G. Dias, personal communication) and are rarely caught in pitfall traps. All species found in the litter during that taxonomic study were also sampled here. Therefore, if there are undetected litter cricket species in the older forest patches, they must be very rare.

The increase in the slopes of the rarefaction curves with regeneration time (Figure 7) indicates an increase in the bias of the estimated species richness with forest regeneration, evidencing an increase in the spatial scale at which species richness is detected. In the most recent forest patches (zero to 15 years of regeneration), species richness was fully sampled, while the rarefaction curves in all remaining, older, patches showed that we did not reach the actual species richness. Therefore, the rarefaction curves reinforce the pattern of species richness increasing with regeneration time.

Our results suggest an apparent saturation of cricket species richness at the sampled spatial scale as well as an increasing complementarity (sensu Colwell and Coddington [86]) of cricket species composition within older forest patches. This may result from an increase in regional species richness, unveiling long-term evolutionary processes. Older forest patches may harbor a larger species pool, which could be traced back to the evolutionary history of the original forest habitat.

\subsection{Effects of Regeneration Time on Cricket Species Com-} position. Although regeneration led to changes in species composition that were coincident with an increase in species richness, composition changes could not be assigned to nestedness; that is, species composition in lower-richness patches was not a subset of species composition in the higher-richness patches (Figure 9). This, along with the differences in composition detected in the NMDS, suggests a directional change in species composition. This coincides with classic definitions of ecological succession [87]. Our results indicate that there may be a directional replacement of species, driven by ecological succession.

4.9. Concluding Remarks. Our results highlight the importance of considering species composition when evaluating biodiversity changes after a disturbance. While the increase in species richness stopped after ca. 130 years of forest regeneration, species composition continued changing. The regeneration that we observed may be restricted to regions where there is a sufficiently large and well-preserved pool of late-succession species that constitute a source of colonizers for regenerating areas. Environmental drivers of biodiversity regeneration probably involve changes in both resource availability and favorable conditions. We believe that the same processes may drive biodiversity regeneration of other organisms, which share a strong dependence on local habitat. A general implication for conservation is that the evaluation of biodiversity recovery necessitates the evaluation of both diversity and species composition responses. Studies that consider only species richness may generate misleading conclusions.

\section{Acknowledgments}

The authors thank Izana Brol, Laércio Szinwelski, Sebastião Oliveira, and Marina Xavier for assistance in the field; Nilsa S. Cardias and Iracema L. S. Brol for help in cricket screening; Sabrina P. Almeida and two anonymous referees for valuable suggestions on the paper; Maria L. Fernandes for help in editing figure. Field facilities were provided by CCZ-Foz do Iguaçu and Iguaçu National Park and financial support by CNPq, CAPES, FAPEMIG, and SISBIOTA (CNPq/FAPEMIG—5653360/2010-0).

\section{References}

[1] J. Vandermeer and I. G. Cerda, "Height dynamics of the thinning canopy of a tropical rain forest: 14 years of succession in a post-hurricane forest in Nicaragua," Forest Ecology and Management, vol. 199, no. 1, pp. 125-135, 2004. 
[2] M. C. Ruiz-Jaen and T. M. Aide, "Restoration success: How is it being measured?" Restoration Ecology, vol. 13, no. 3, pp. 569-577, 2005.

[3] L. Meneses-Calvillo, V. M. Ramírez, V. Parra-Tabla, and J. Navarro, "Bee diversity in a fragmented landscape of the Mexican neotropic," Journal of Insect Conservation, vol. 14, no. 4, pp. 323-334, 2010.

[4] N. Myers, R. A. Mittermeler, C. G. Mittermeler, G. A. B. Fonseca, and J. Kent, "Biodiversity hotspots for conservation priorities," Nature, vol. 403, no. 6772, pp. 853-858, 2000.

[5] B. S. van Gemerden, G. N. Shu, and H. Olff, "Recovery of conservation values in Central African rain forest after logging and shifting cultivation," Biodiversity and Conservation, vol. 12, no. 8, pp. 1553-1570, 2003.

[6] B. G. Ferguson, J. Vandermeer, H. Morales, and D. M. Griffith, "Post-agricultural succession in El Petén, Guatemala," Conservation Biology, vol. 17, no. 3, pp. 818-828, 2003.

[7] E. R. Hooper, P. Legendre, and R. Condit, "Factors affecting community composition of forest regeneration in deforested, abandoned land in Panama," Ecology, vol. 85, no. 12, pp. 33133326, 2004.

[8] R. R. Dunn, "Recovery of faunal communities during tropical forest regeneration," Conservation Biology, vol. 18, no. 2, pp. 302-309, 2004.

[9] D. Veddeler, C. H. Schulze, I. Steffan-Dewenter, D. Buchori, and T. Tscharntke, "The contribution of tropical secondary forest fragments to the conservation of fruit-feeding butterflies: effects of isolation and age," Biodiversity and Conservation, vol. 14, no. 14, pp. 3577-3592, 2005.

[10] S. J. Wright and H. C. Muller-Landau, "The future of tropical forest species," Biotropica, vol. 38, no. 3, pp. 287-301, 2006.

[11] I. M. Turner and R. T. Corlett, "The conservation value of small, isolated fragments of lowland tropical rain forest," Trends in Ecology and Evolution, vol. 11, no. 8, pp. 330-333, 1996.

[12] R. L. Chazdon, C. A. Peres, D. Dent et al., "The potential for species conservation in tropical secondary forests," Conservation Biology, vol. 23, no. 6, pp. 1406-1417, 2009.

[13] M. R. Guariguata and R. Ostertag, "Neotropical secondary forest succession: changes in structural and functional characteristics," Forest Ecology and Management, vol. 148, no. 1-3, pp. 185-206, 2001.

[14] W. Zhu, S. Cheng, X. Cai, F. He, and J. Wang, "Changes in plant species diversity along a chronosequence of vegetation restoration in the humid evergreen broad-leaved forest in the Rainy Zone of West China," Ecological Research, vol. 24, no. 2, pp. 315-325, 2009.

[15] F. E. Clements, "Nature and structure of the climax," The Journal of Ecology, vol. 24, no. 1, pp. 252-284, 1936.

[16] R. Michalet, R. W. Brooker, L. A. Cavieres et al., "Do biotic interactions shape both sides of the humped-back model of species richness in plant communities?" Ecology Letters, vol. 9, no. 7, pp. 767-773, 2006.

[17] F. E. Egler, "Vegetation science concepts I. Initial floristic composition, a factor in old-field vegetation development with 2 figs," Vegetatio Acta Geobotanica, vol. 4, no. 6, pp. 412-417, 1954.

[18] A. N. Auclair and F. G. Goff, "Diversity relations of upland forests in the western Great Lakes area," The American Naturalist, vol. 105, no. 946, pp. 499-528, 1971.

[19] J. P. Grime, "Competitive exclusion in herbaceous vegetation," Nature, vol. 242, no. 5396, pp. 344-347, 1973.

[20] M. Huston, "A general hypothesis for species diversity," American Naturalist, vol. 113, no. 1, pp. 81-101, 1979.
[21] J. S. Denslow, "Patterns of plant species diversity during succession under different disturbance regimes," Oecologia, vol. 46, no. 1, pp. 18-21, 1980.

[22] S. M. Scheiner and M. R. Willig, "Developing unified theories in ecology as exemplified with diversity gradients," The American Naturalist, vol. 166, no. 4, pp. 458-469, 2005.

[23] C. F. Sperber, L. G. S. Soares, and M. R. Pereira, "Litter disturbance and trap spatial positioning affects number of captured individuals and genera of crickets (Orthoptera: Grylloidea)," Journal of Orthoptera Research, vol. 16, no. 1, pp. 77-83, 2007.

[24] K. E. McCluney and R. C. Date, "The effects of hydration on growth of the house cricket, Acheta domesticus," Journal of Insect Science, vol. 8, no. 32, pp. 1-9, 2008.

[25] W. F. Laurance, T. E. Lovejoy, H. L. Vasconcelos et al., "Ecosystem decay of Amazonian forest fragments: a 22-year investigation," Conservation Biology, vol. 16, no. 3, pp. 605$618,2002$.

[26] C. T. Rizzini, Tratado de fitogeografia do Brasil: aspectos ecológicos, sociológicos e florísticos, Âmbito Cultural, Rio de Janeiro, Brazil, 2nd edition, 1997.

[27] A. E. Guimarães, C. M. Lopes, R. P. Mello, and J. Alencar, "Ecologia de mosquitos (Diptera, Culicidae) em áreas do Parque Nacional do Iguaçu, Brasil. 1 Distribuição por hábita," Caderno de Saúde Pública, vol. 19, no. 4, pp. 1107-1116, 2003.

[28] Google Earth. Foz do Iguaçu, Brazil, 2008.

[29] R. Salamuni, E. Salamuni, L. A. Rocha, and A. L. Rocha, "Parque Nacional do Iguaçu, PR — ataratas de fama mundial," Sítios geológicos e paleontológicos do Brasil, pp. 313-321, 2002.

[30] R. A. Ortiz, "Conservation versus development at the Iguaçu National Park, Brazil," Ambientalia, vol. 1, pp. 141-160, 2010.

[31] J. R. Muñoz, "The guerra grande: the war of the Triple Alliance, 1865-1870," Strategy \& Tactics, vol. 270, pp. 6-18, 2011.

[32] IBAMA, Plano de Manejo do Parque Nacional do Iguaçu, MMA, Brasília-DF, 1999.

[33] C. F. Sperber, G. H. Vieira, and M. H. Mendes, "Aprimoramento da amostragem de grilos de serapilheira (Orthoptera: Gryllidae) por armadilha," Neotropical Entomology, vol. 32, no. 4, pp. 733-735, 2003.

[34] G. W. Frazer, C. D. Canham, and K. P. Lertzman, Gap Light Analyzer Analyzer (GLA): Imaging Software to Extract Canopy Structure and Gap Light Transmission Indices From Truecolour Fisheye phoTographs, User Manual and Program Documentation, Simon Fraser University, British Colombia, Canda, Institute of Ecossystem Studies, New York, NY, USA, 1999.

[35] M. J. Crawley, The R Book, John Wiley \& Sons, West Sussex, UK, 2007.

[36] A. F. Zuur, E. N. Ieno, N. J. Walker, A. A. Saveliev, and G. M. Smith, Mixed Effects Models and Extensions in Ecology With R, Springer, New York, NY, USA, 2009.

[37] B. D. Coleman, "On random placement and species-area relations," Mathematical Biosciences, vol. 54, no. 3-4, pp. 191215, 1981.

[38] R Development Core Team, R: A Language and Environment for Statisticalstatistical Computing, R Foundation for Statistical Computing, Vienna, Austria, 2010.

[39] N. J. Gotelli and R. K. Colwell, "Quantifying biodiversity: procedures and pitfalls in the measurement and comparison of species richness," Ecology Letters, vol. 4, no. 4, pp. 379-391, 2001. 
[40] R. K. Colwell, EstimateS—Statistical Estimation of Species Richness and Shared Species from Samples, Version 7.5, University of Connecticut, Storrs, Conn, USA, 2005.

[41] K. R. Clarke, "Non-parametric multivariate analyses of changes in community structure," Australian Journal of Ecology, vol. 18, no. 1, pp. 117-143, 1993.

[42] Ø. Hammer, D. A. T. Harper, and P. D. Ryan, "Past: paleontological statistics software package for education and data analysis," Palaeontologia Electronica, vol. 4, no. 1, pp. 1-9, 2001.

[43] B. D. Patterson and W. Atmar, "Nested subsets and the structure of insular mammalian faunas and archipelagos," Biological Journal of the Linnean Society, vol. 28, no. 1-2, pp. 65-82, 1986.

[44] W. Ulrich, M. Almeida-Neto, and N. J. Gotelli, “A consumer's guide to nestedness analysis," Oikos, vol. 118, no. 1, pp. 3-17, 2009.

[45] J. Oksanen, R. Kindt, P. Legendre, B. O’Hara, and G. L. Simpson, "Vegan: Community Ecology Package. R package version 1.15-4," 2009.

[46] M. Almeida-Neto, P. Guimarães, P. R. Guimarães Jr., R. D. Loyola, and W. Ulrich, "A consistent metric for nestedness analysis in ecological systems: reconciling concept and measurement," Oikos, vol. 117, no. 8, pp. 1227-1239, 2008.

[47] L. N. Joppa, J. M. Montoya, R. Solé, J. Sanderson, and S. L. Pimm, "On nestedness in ecological networks," Evolutionary Ecology Research, vol. 12, no. 1, pp. 35-46, 2010.

[48] R. C. Paul and T. J. Walker, "Arboreal singing in a burrowing cricket, Anurogryllus arboreus," Journal of Comparative Physiology A, vol. 132, no. 3, pp. 217-223, 1979.

[49] D. G. Richards and R. H. Wiley, "Reverberations and amplitude fluctuations in the propagation of sound in a forest: implications for animal communication," The American Naturalist, vol. 115, no. 3, pp. 381-399, 1980.

[50] T. Yamada and S. Yoshimura, "Line search partitioned approach for fluid-structure interaction analysis of flapping wing," Computer Modeling in Engineering \& Sciences, vol. 24, no. 1, pp. 51-60, 2008.

[51] L. Desutter-Grandcolas, "Phylogeny and the evolution of acoustic communication in extant Ensifera (Insecta, Orthoptera)," Zoologica Scripta, vol. 32, no. 6, pp. 525-561, 2003.

[52] M. J. van Staaden and H. Römer, "Sexual signalling in bladder grasshoppers: tactical design for maximizing calling range," Journal of Experimental Biology, vol. 200, no. 20, pp. 25972608, 1997.

[53] L. Desutter-Grandcolas, "A phylogenetic analysis of the evolution of the stridulatory apparatus in true crickets (Orthoptera, Grylloidea)," Cladistics, vol. 13, no. 1-2, pp. 101-108, 1997.

[54] T. Robillard and L. Desutter-Grandcolas, "A revision of neotropical Eneopterinae crickets (Orthoptera, Grylloidea, Eneopteridae) with a phylogenetic discussion," Insect Systematics and Evolution, vol. 35, no. 4, pp. 411-435, 2004.

[55] E. Zefa, F. M. Rúbio, A. R. Rinaldi, L. H. Gollin, D. B. F. Silva, and P. G. B. S. Dias, "Seasonal life cycle of the tropical cricket Eneoptera surinamensis (Orthoptera, Gryllidae, Eneopterinae)," Iheringia. Série Zoologia, vol. 96, no. 2, pp. 267-269, 2006.

[56] C. M. Mews and C. F. Sperber, "A new species of Endecous Saussure, 1878 and redescription of Endecous cavernicolus Costa-Lima, 1940 (Orthoptera: Grylloidea: Phalangopsidae)," Studies on Neotropical Fauna and Environment, vol. 43, no. 2, pp. 159-167, 2008.
[57] C. R. Ribas, T. G. Sobrinho, J. H. Schoereder, C. F. Sperber, C. Lopes-Andrade, and S. M. Soares, "How large is large enough for insects? Forest fragmentation effects at three spatial scales," Acta Oecologica, vol. 27, no. 1, pp. 31-41, 2005.

[58] A. N. Ab'Sáber, “The natural organization of Brazilian interand subtropical landscapes," Revista do Instituto Geológico, vol. 21, no. 1-2, pp. 57-70, 2000.

[59] Z. Ting and P. Shaolin, "Spatial scale and measurement of edge effect in ecology," Acta Ecologica Sinica, vol. 28, no. 7, pp. 3322-3333, 2008.

[60] O. T. Lewis, "Effect of experimental selective logging on tropical butterflies," Conservation Biology, vol. 15, no. 2, pp. 389-400, 2001.

[61] L. Fahrig, "How much habitat is enough?" Biological Conservation, vol. 100, no. 1, pp. 65-74, 2001.

[62] M. L. Rosenzweig, Species Diversity in Space and Time, Cambridge University Press, Cambridge, Mass, USA, 1995.

[63] F. M. Salzano and S. M. Callegari-Jacques, South American Indians: A Case Study in Evolution, Oxford Science Publications, Oxford University Press, New York, NY, USA, 1988.

[64] D. A. Posey, "Ethnomethodology as an EMIC guide to cultural systems: the case of insects and the Kayapó indians of Amazonia," Revista Brasileira de Zoologia, vol. 1, no. 3, pp. 135-144, 1983.

[65] D. A. Posey, Kayapó Ethnoecology and Culture, Taylor \& Francis, Routledge, UK, 2002.

[66] N. C. Brouwers and A. C. Newton, "Habitat requirements for the conservation of wood cricket (Nemobius sylvestris) (Orthoptera: Gryllidae) on the Isle of Wight, UK," Journal of Insect Conservation, vol. 13, no. 5, pp. 529-541, 2009.

[67] W. P. Carson and R. B. Root, "Top-down effects of insect herbivores during early succession: influence on biomass and plant dominance," Oecologia, vol. 121, no. 2, pp. 260-272, 1999.

[68] W. H. G. Hol, W. de Boer, A. J. Termorshuizen et al., "Reduction of rare soil microbes modifies plant-herbivore interactions," Ecology Letters, vol. 13, no. 3, pp. 292-301, 2010.

[69] R. Ejrnæs, D. N. Hansen, and E. Aude, "Changing course of secondary succession in abandoned sandy fields," Biological Conservation, vol. 109, no. 3, pp. 343-350, 2003.

[70] J. A. Onsager, "Suppression of grasshoppers in the Great Plains through grazing management," Journal of Range Management, vol. 53, no. 6, pp. 592-602, 2000.

[71] D. Renault, O. Nedved, F. Hervant, and P. Vernon, "The importance of fluctuating thermal regimes for repairing chill injuries in the tropical beetle Alphitobius diaperinus (Coleoptera: Tenebrionidae) during exposure to low temperature," Physiological Entomology, vol. 29, no. 2, pp. 139-145, 2004.

[72] J. S. Terblanche, E. Marais, and S. L. Chown, "Stage-related variation in rapid cold hardening as a test of the environmental predictability hypothesis," Journal of Insect Physiology, vol. 53, no. 5, pp. 455-462, 2007.

[73] S. L. Elliot, C. M. Horton, S. Blanford, and M. B. Thomas, "Impacts of fever on locust life-history traits: costs or benefits?" Biology Letters, vol. 1, no. 2, pp. 181-184, 2005.

[74] W. Federle, M. Riehle, A. S. G. Curtis, and R. J. Full, "An integrative study of insect adhesion: mechanics and wet adhesion of pretarsal pads in ants," Integrative and Comparative Biology, vol. 42, no. 6, pp. 1100-1106, 2002.

[75] W. Federle and T. Endlein, "Locomotion and adhesion: dynamic control of adhesive surface contact in ants," Arthropod Structure \& Development, vol. 33, no. 1, pp. 67-75, 2004. 
[76] T. R. E. Southwood, "Habitat, the templet for ecological strategies?" The Journal of Animal Ecology, vol. 46, no. 2, pp. 336-365, 1977.

[77] H. A. Woods, "Water loss and gas exchange by eggs of Manduca sexta: trading off costs and benefits," Journal of Insect Physiology, vol. 56, no. 5, pp. 480-487, 2010.

[78] F. Roces and C. Kleineidam, "Humidity preference for fungus culturing by workers of the leaf-cutting ant Atta sexdens rubropilosa," Insectes Sociaux, vol. 47, no. 4, pp. 348-350, 2000.

[79] T. Steenberg, V. Langer, and P. Esbjerg, "Entomopathogenic fungi in predatory beetles (Col.: Carabidae and Staphylinidae) from agricultural fields," Entomophaga, vol. 40, no. 1, pp. 7785, 1995.

[80] J. Z. Shik and M. Kaspari, "More food, less habitat: How necromass and leaf litter decomposition combine to regulate a litter ant community," Ecological Entomology, vol. 35, no. 2, pp. 158-165, 2010.

[81] M. F. Barberena-Arias and T. M. Aide, "Species diversity and trophic composition of litter insects during plant secondary succession," Caribbean Journal of Science, vol. 39, no. 2, pp. 161-169, 2003.

[82] B. K. Williams, T. A. G. Rittenhouse, and R. D. Semlitsch, "Leaf litter input mediates tadpole performance across forest canopy treatments," Oecologia, vol. 155, no. 2, pp. 377-384, 2008.

[83] G. H. Kattan, D. Correa, F. Escobar, and C. Medina, "Leaflitter arthropods in restored forests in the Colombian Andes: a comparison between secondary forest and tree plantations," Restoration Ecology, vol. 14, no. 1, pp. 95-102, 2006.

[84] F. Huber, T. E. Moore, and W. Loher, Cricket Behavior and Neurobiology, Cornell University Press, New York, NY, USA, 1989.

[85] C. E. Prescott, "Effects of clearcutting and alternative silvicultural systems on rates of decomposition and nitrogen mineralization in a coastal montane coniferous forest," Forest Ecology and Management, vol. 95, no. 3, pp. 253-260, 1997.

[86] R. K. Colwell and J. A. Coddington, "Estimating terrestrial biodiversity through extrapolation," Philosophical Transactions of the Royal Society of London, vol. 345, no. 1311, pp. 101-118, 1994.

[87] M. Begon, C. R. Townsend, and J. L. Harper, Ecology: From Individuals to Ecosystems, Blackwell, Oxford, UK, 4th edition, 2006. 

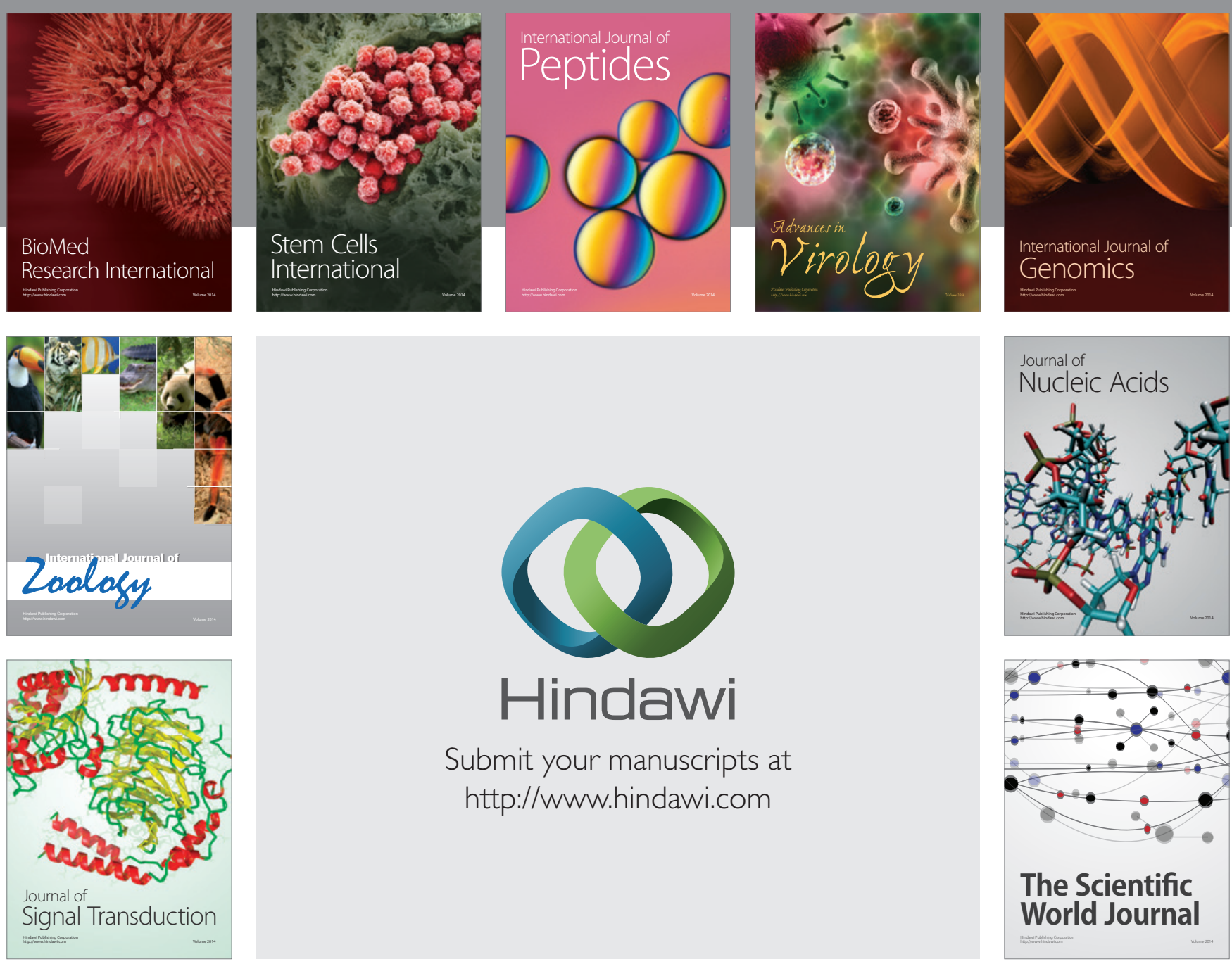

Submit your manuscripts at

http://www.hindawi.com
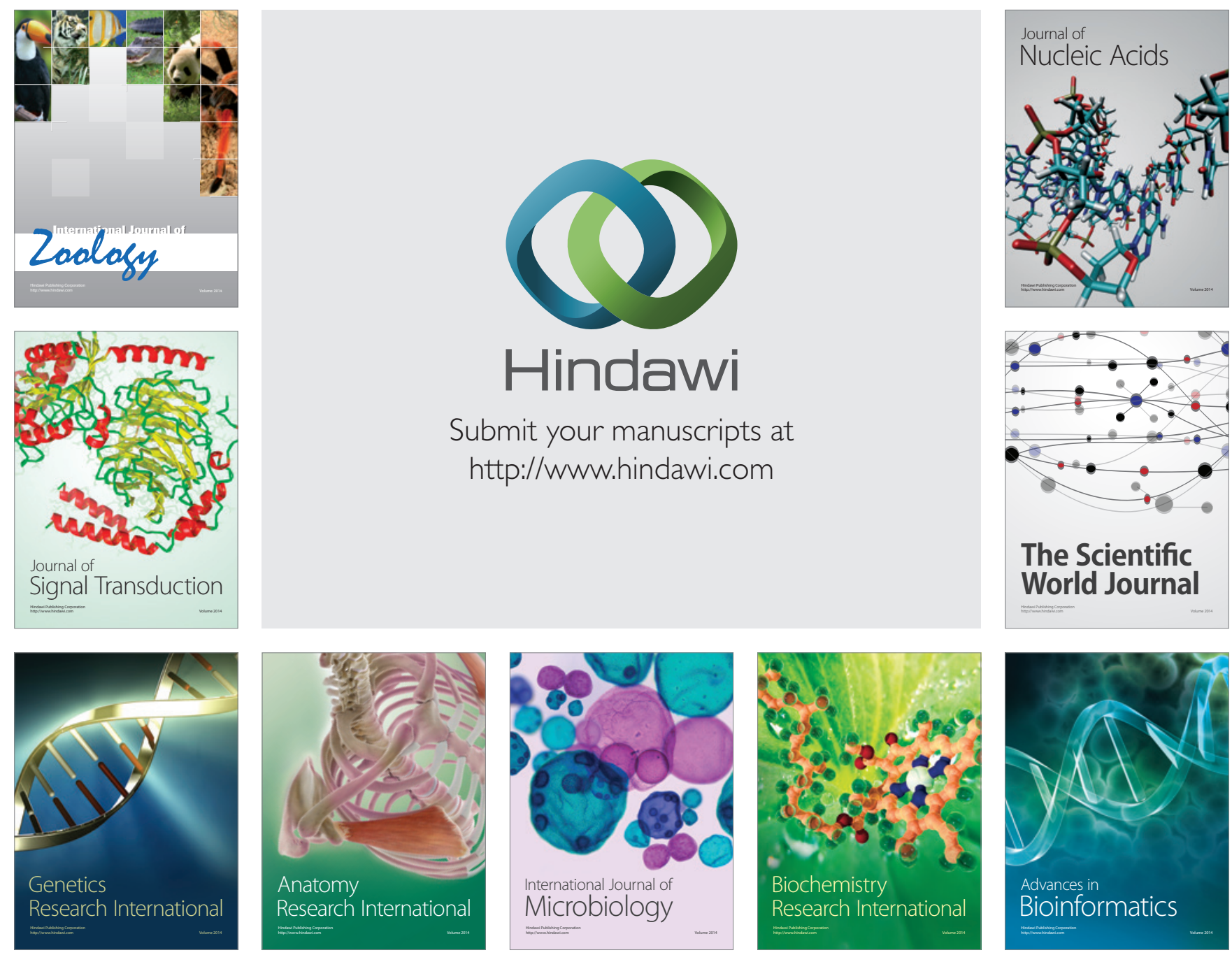

The Scientific World Journal
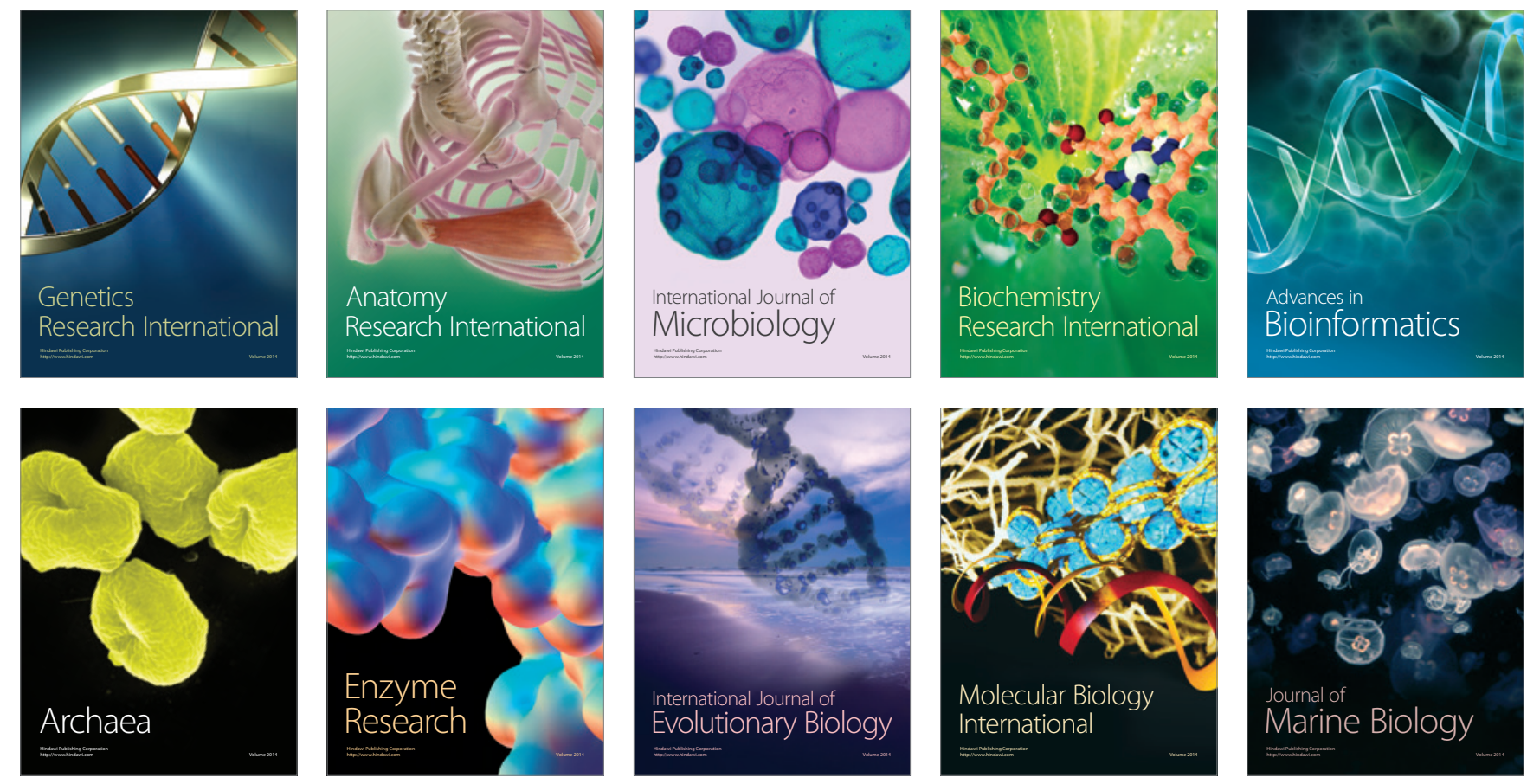